Article

\title{
Experimental Investigations of the Ignitability of Several Coal Dust Qualities
}

\author{
Reyhane Youssefi $^{1, *(\mathbb{D})}$, Tom Segers ${ }^{2}$, Frederik Norman ${ }^{2}$, Jörg Maier ${ }^{1}$ and Günter Scheffknecht ${ }^{1}$ (D) \\ 1 University of Stuttgart, Institute of Combustion and Power Plant Technology, Pfaffenwaldring 23, \\ 70569 Stuttgart, Germany; joerg.maier@ifk.uni-stuttgart.de (J.M.); \\ guenter.scheffknecht@ifk.uni-stuttgart.de (G.S.) \\ 2 Adinex N.V., Brouwerijstraat 11, Noorderwijk-Herentals, B-2200 Herentals, Belgium; \\ tom.segers@adinex.be (T.S.); frederik.norman@adinex.be (F.N.) \\ * Correspondence: reyhane.youssefi@ifk.uni-stuttgart.de
}

Citation: Youssefi, R.; Segers, T.; Norman, F.; Maier, J.; Scheffknecht, G. Experimental Investigations of the Ignitability of Several Coal Dust Qualities. Energies 2021, 14, 6323. https://doi.org/10.3390/en14196323

Academic Editor: Andrzej Teodorczyk

Received: 26 August 2021

Accepted: 27 September 2021

Published: 3 October 2021

Publisher's Note: MDPI stays neutral with regard to jurisdictional claims in published maps and institutional affiliations.

Copyright: (c) 2021 by the authors. Licensee MDPI, Basel, Switzerland. This article is an open access article distributed under the terms and conditions of the Creative Commons Attribution (CC BY) license (https:// creativecommons.org/licenses/by/ $4.0 /)$
Abstract: The ignition characteristics of coal dust is of high importance for the flame stability in coal-fired power plants. We investigate the ignitability of six lignite dust qualities and one hard coal using dust explosion tests and an ignitability characteristic number. The paper aims to identify the degree of impact of the properties of coals, such as the moisture content, the ash content etc., on the ignition characteristics and ultimately to compare the identified relevant ignition parameters to the ignition performance of the dust qualities in an industrially relevant environment. The minimum cloud ignition temperature (MCIT), the maximum rate of pressure rise $\left((d p / d t)_{\max }\right)$, the maximum explosion pressure $\left(p_{\max }\right)$, the deflagration index $\left(\mathrm{K}_{\mathrm{st}_{\mathrm{t}}}\right.$-value) and the modified ignitability characteristic number $\left(\mathrm{ZWZ}_{\text {mod. }}\right)$ were determined and were attributed to the moisture content, the ash content and the median particle size. The MCIT was largely influenced by the volatile content, whereas the variations of moisture and ash contents within the range of $10 \%$ to $20 \%$ did not have a significant impact on the MCIT. The maximum explosion pressure did not differ considerably and stayed in a narrow range among the tested dust qualities. The deflagration index showed a higher sensitivity to the dust properties. The deflagration index and the modified ignitability characteristics number dropped as the moisture content increased and the volatile content reduced. The $\mathrm{K}_{\text {st }}$ and $\mathrm{ZWZ}$ mod. values showed the highest susceptibility to the coal dust properties. Hence, they were used as representative parameters for further comparison with the ignition performance of coal dust in a pilot-scale testing. The results showed that both parameters predicted the ignition performance relatively well and can be used as indicators for the prediction of the ignition performance.

Keywords: dust explosion characteristics; the ignitability characteristic number; lignite dust; moisture content; ash content; median particle size

\section{Introduction}

In pulverized fuel systems, the ignitability of the fuel plays an important role in the combustion efficiency and the flame stability. In coal-fired power plants, the flame stability and, consequently, the plant efficiency deteriorate when the temperature inside the furnace drops during part-load operation or when the fuel quality varies notably from the standard fuel designed for that firing system. In industrial burners during the plant start-up, solid fuel is ignited via supporting burners, e.g., natural gas burners, where the surrounding temperature is notably above the temperature required for dust ignition. As the result, the solid dust particles ignite once they enter the combustion chamber.

A novel technology to initiate coal dust ignition in solid fuel burners is plasma-assisted ignition and combustion. During cold power plant start-up, the solid fuel particles are ignited with a plasma torch in an ambient-temperature-environment. The plasma torch ignites a portion of the solid fuel stream and the resulting flame propagates through the dust cloud [1,2]. 
The fuel ignition characteristics have high relevance as the fuel is ignited under such extreme conditions, i.e., when a small amount of heat is available for the ignition. Under these circumstances, it is crucial to characterize the ignitability of fuels to design the firing system and to adjust the boundary conditions accordingly. The ignition initiation for fuels with low ignitability is challenging, while fuels with high ignitability serve as suitable candidates for this application.

There are laboratory equipment and test methods that assess the explosibility and the ignitability of dust. Dust explosion parameters are usually determined to support the design of safety systems in industrial processes and to minimize the explosion hazard. These explosion parameters are also relevant for characterizing the dust ignitability and flame propagation. In this study, dust explosion characteristics are used to outline the ignitability of different coal dust qualities.

The minimum cloud ignition temperature (MCIT), maximum explosion pressure $\left(p_{\max }\right)$, the maximum rate of pressure rise $\left((d p / d t)_{\max }\right)$ and deflagration index $\left(\mathrm{K}_{\mathrm{st}}\right.$-value $)$ are investigated in this work. In addition to the dust explosion parameters, a characteristic number, in this work defined as a modified ignitability characteristic number, introduced initially by Zelkowski [3] known as "Zündwilligkeitkenzahl (ZWZ)", is used to describe the ignition tendency of solid fuels. Zelkowski showed that the ignitability characteristic number suggests promising results for categorizing various hard coal and lignite qualities [3]. The ignition characteristic number aims to distinguish the ignition behaviour between solid fuel types, such as hard coal, lignite, etc. However, its relevance for differentiating the ignitability of one fuel type's distinct grades has not been investigated extensively.

The ignition characteristics are a function of fuel chemical composition, such as volatile, moisture and ash contents and physical properties, e.g., particle size, particle shape and surface area. Torrent et al. [4,5] developed a correlation between the fuel composition and the explosibility of coal dust, in which the fuels were categorized into three groups based on the explosion hazard and were found to be most influenced by the volatile content. However, in the study no physical properties were taken into account [4,5]. The particle size is a decisive parameter for ignition and explosion characteristics of dust, as ignition can be completely hindered by coarse particles [6].

Given the chemical properties, the volatile content is considered the most relevant parameter for the ignitability and explosibility of dusts [6,7]. Water and ash in coal are known to reduce the ignition susceptibility. The utilization of inert material has been widely employed as a measure to suppress the explosion. However, a significant share of inert dust is required to inhibit the ignition [8,9]. Water represents a stronger inhibiting effect compared with ash [10]. Heat consumption for endothermic water evaporation is determined as the main ignition inhibition mechanism by water. In addition, particle agglomeration at high moisture contents and reducing the oxygen particle pressure in the boundary layer around the particles are expected to reduce the explosibility [10-13].

Within the literature, the effect of volatiles, moisture and ash content on dust explosion parameters have been mainly focused on ignition inhibition to prevent explosion hazards. The potential of these parameters to indicate the dust ignitability and flame propagation have not been extensively investigated. In addition, the studies that have been investigated the explosibility of dust consider only the fine share of particles and therefore the effect of particle size is disregarded. The variations in the investigated parameters between different qualities of one solid fuel type, e.g., lignite, have not been addressed in previous studies.

More importantly, these parameters are determined under laboratory conditions, which differ significantly from the boundary conditions applied in industrially-relevant environments. It is required to investigate these parameters to identify which one has the highest relevance to industrial-scale applications and can be used in practice to predict the ignition behaviour. To identify the suitable fuel quality with an adequate level of ignitability for the application of start-ups with plasma-assisted ignition, several lignite qualities and one hard coal are studied. 
The lignite qualities differ notably in the moisture and ash content, as well as the median particle size. This work aims to understand the extent to which the ignition parameters vary with regard to the fuel chemical and physical properties and to eventually determine the most relevant parameters to characterize the ignitability of the investigated fuel qualities. Ultimately, the study correlates these parameters to the ignition performance observed in pilot-scale experiments. The investigation of pilot-scale plasma-assisted ignition is thoroughly discussed in another publication by Youssefi et al. [14].

\section{Materials and Methods}

\subsection{Materials}

Six pre-dried lignites, originating from different mines in Germany, and one South African hard coal were investigated. Table 1 shows the ultimate analysis and heating values of the fuels. The lignites were received pre-dried with a moisture content ranging from $10 \%$ to $30 \%$. Lignite A, B and C were obtained from a common mine but underwent different pre-drying processes.

Table 1. Chemical properties.

\begin{tabular}{|c|c|c|c|c|}
\hline \multirow{3}{*}{ Fuel } & NCV & $\gamma_{\mathrm{H}_{2} \mathrm{O}}$ & $\gamma_{A}$ & $\gamma_{\text {volatile }}$ \\
\hline & \multicolumn{4}{|c|}{ Raw } \\
\hline & $\mathrm{MJ} / \mathrm{kg}$ & \multicolumn{3}{|c|}{$10^{-2} \mathrm{~kg} / \mathrm{kg}(\%)$} \\
\hline Lignite A & 20.8 & 10.5 & 5.0 & 48.5 \\
\hline Lignite B & 20.2 & 14.5 & 4.7 & 46.4 \\
\hline Lignite C & 18.8 & 19.4 & 4.0 & 43.8 \\
\hline Lignite D & 15.8 & 20.2 & 12.5 & 42.6 \\
\hline Lignite F & 12.2 & 29.3 & 19.6 & 32.5 \\
\hline Lignite G & 19.6 & 12.6 & 15.5 & 44.7 \\
\hline Hard coal & 25.9 & 2.6 & 15.2 & 26.2 \\
\hline
\end{tabular}

The samples sieved with a $0.5 \mathrm{~mm}$ mesh size were used for dust explosion tests and the determination of ignitability characteristic number. For the pilot-scale experiments, the samples were sieved with a $2 \mathrm{~mm}$ mesh size. The volumetric particle size distribution was measured by the laser diffraction principle using Malvern Mastersize 3000 analyser and Horiba LA-950 analyser for samples sieved by $2 \mathrm{~mm}$ mesh size and $0.5 \mathrm{~mm}$ mesh size, respectively. Table 2 shows the characteristic parameters of the size distribution and the specific surface area. The specific surface area of selected lignite qualities from the $0.5 \mathrm{~mm}$ sample was determined based on the gas sorption principle and using the BET calculation method. As can be seen, the dust samples represent large variations in the specific surface area ranging from 0.56 to $19.8 \mathrm{~m}^{2} / \mathrm{g}$.

Table 2. Physical properties.

\begin{tabular}{|c|c|c|c|c|c|c|c|}
\hline \multirow{3}{*}{ Fuel } & $D 10$ & D50 & $D 90$ & $D 10$ & D50 & D90 & $a$ \\
\hline & \multicolumn{3}{|c|}{$0.5 \mathrm{~mm}$ Sieved } & \multicolumn{3}{|c|}{$2 \mathrm{~mm}$ Sieved } & \\
\hline & \multicolumn{6}{|c|}{$\mu \mathrm{m}$} & $\mathrm{m}^{2} / \mathrm{g}$ \\
\hline Lignite A & 5 & 46 & 184 & & & & 0.56 \\
\hline Lignite B & 19 & 83 & 225 & 42 & 320 & 1500 & \\
\hline Lignite C & 22 & 149 & 402 & 31 & 366 & 1600 & 1.79 \\
\hline Lignite D & 15 & 128 & 503 & 34 & 420 & 1726 & 19.8 \\
\hline Lignite F & 18 & 173 & 520 & 73 & 667 & 1935 & 5.0 \\
\hline Lignite G & 8 & 80 & 337 & 31 & 551 & 1143 & 15.5 \\
\hline Hard coal & 5 & 40 & 158 & & & & \\
\hline
\end{tabular}




\subsection{Method}

MCIT tests were performed in the BAM-oven according to the standard procedure in the VDI 2263, Part 1 [15]. Based on VDI 2263, it is recommended to use samples with particle sizes smaller than $63 \mu \mathrm{m}$. However, since the results need to be eventually correlated with pilot-scale experiments, samples with coarser particle sizes (below $500 \mu \mathrm{m}$ )++ more similar to those used in the pilot-scale experiments, were considered in this study. The dust sample was dispersed using air in an horizontal electrically-heated oven against an impact plate located in the oven center.

The oven was heated up to its maximum temperature of $600{ }^{\circ} \mathrm{C}$, and tests were performed at $10 \mathrm{~K}$ descending intervals. The test was demonstrated for three dust concentrations. The lowest temperature at which ignition occurs within a 10 s-delay time is considered as the minimum cloud ignition temperature. However, the ignition was normally accomplished in less than one second. According to the EN 80079-20-2 [16], the minimum cloud ignition temperature is defined as the lowest temperature at which ignition occurs, reduced by $20 \mathrm{~K}$ for temperatures above $300{ }^{\circ} \mathrm{C}$ and by $10 \mathrm{~K}$ for temperatures below $300{ }^{\circ} \mathrm{C}$. The minimum ignition temperatures reported in this work are per the EN 80079-20-2.

The explosion characteristics of dust clouds were determined according to the standards of VDI 2263-part 1 [15], EN14034-1 [17] and 14034-2 [18]. The Siwek 20-Litre sphere was used, in which the dust sample was dispersed and ignited via two pyrotechnic igniters of $5 \mathrm{~kJ}$ each, located in the center of the sphere. The pressure was measured and recorded continuously during the explosion tests using two piezoelectric pressure sensors. $p_{\mathrm{m}}$ is the corrected value of the explosion pressure, taking into account the cooling effect from the sphere wall.

The rate of pressure rise was calculated from the slope of the tangent point in the dynamic graph of the pressure for each explosion test. The explosion tests were performed at several dust concentrations. The maximum value of the explosion pressure and the maximum rate of pressure rise, over the dust concentration tested, are identified as $p_{\max }$ and $(d p / d t)_{\max }$, respectively. To compare the explosibility at different test spheres, a volumeindependent parameter is derived, where the maximum rate of pressure rise is multiplied to the sphere volume's cube root, known as the dust deflagration index $\left(\mathrm{K}_{\mathrm{st}}\right.$-value).

The original ignitability characteristic number (ZWZ) is defined as the ratio of ignition potential $\left(\mathrm{N}_{Z 500}\right)$ to the ignition temperature. The ignition potential was described as the energy of volatile matters, released from a water-free coal sample through the devolatilization process up to the temperature of $500{ }^{\circ} \mathrm{C}$. The ignition temperature in the above definition was specified as the minimum temperature at which a dust cloud of particles below $63 \mu \mathrm{m}$ ignites within $150 \mathrm{~ms}$ [3]. The use of ignition potential on a water-free basis is more relevant for comparing the ignitability between different coal ranks that mainly differ in their degree of coalification and correspondingly the volatile matter.

However, when fuels have similar rank and differ considerably in their inert content, particularly moisture content, the initial energy released by volatiles is first consumed for the water evaporation. Therefore, the ignition potential determined on the raw fuel basis was found to be more relevant in this work when lignites with distinct water contents were concerned. The modified ignitability characteristic number $\left(\mathrm{ZWZ}_{\text {mod. }}\right)$ developed in this study was defined as the ratio of ignition potential on the raw fuel basis $\left(\mathrm{N}_{Z 500 \text {, raw }}\right)$ to the minimum cloud ignition temperature determined in accordance to the EN 80079 standard.

The performance of lignites and hard coal in the plasma-assisted ignition burner was evaluated with a parameter called "Combustion Class". The Combustion Class characterizes the status of ignition and self-sustained flame formation of six classes. The performance reduces from Combustion Class 6 to Combustion Class 0. Combustion Class 5 and 6 represent the formation of a detached and an attached self-sustained flame with shorttime plasma-assisted ignition, respectively. The fuels with Combustion Class 5 and 6 demonstrate high devolatilization and were found suitable to be used as a start-up fuel in this application. 
Combustion Class 3 describes the formation of a coherent flame only during plasmasupported combustion, whereas Combustion Class 1 and 2 indicate that a coherent flame is not formed under the investigated operational conditions. A detailed description of the methodology of plasma-assisted ignition experiments as well as the Combustion Class and the ignition performance can be found elsewhere [14].

\section{Results and Discussion}

\subsection{Minimum Cloud Ignition Temperature (MCIT)}

Figure 1 illustrates the MCIT of lignites in ascending order. On the left axis is the $\mathrm{MCIT}$, and, on the right axis, the moisture content, ash content and the median particle size of sieved samples are shown. Except for Lignite F with $32 \%$ volatile content, the other five lignite qualities have a comparable volatile content of $43 \%$ to $48 \%$.

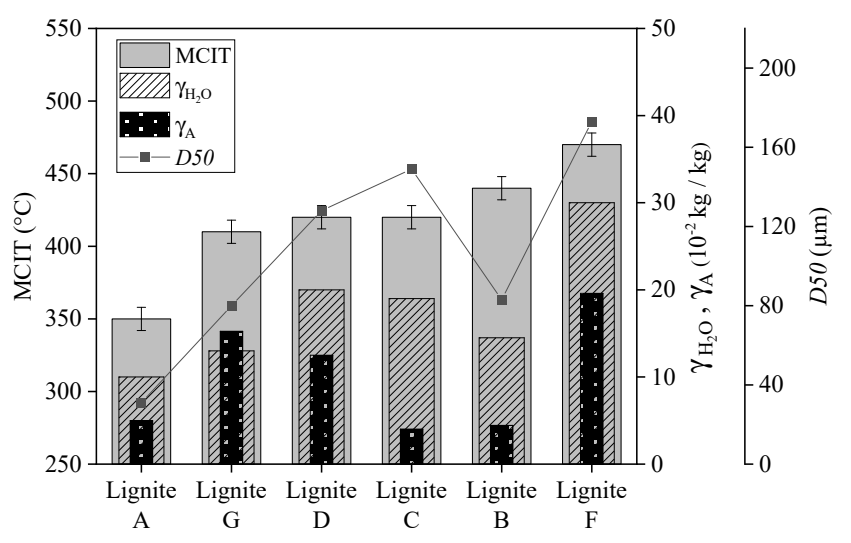

Figure 1. Minimum cloud ignition temperature (MCIT) of lignite qualities in ascending order, left axis: MCIT, first right axis: moisture and ash content, second right axis: median particle size.

It can be seen that Lignite A and Lignite F, representing the smallest and largest median particle size and the lowest and the highest moisture and ash content, respectively, stand for the minimum and maximum MCIT of $350{ }^{\circ} \mathrm{C}$ and $470{ }^{\circ} \mathrm{C}$ among the tested lignites.

Lignite $\mathrm{G}$ has the second-lowest MCIT of $410{ }^{\circ} \mathrm{C}$, as the physical and chemical properties concerning ignitability are exacerbated with regard to Lignite A. Comparing Lignite $\mathrm{G}$ with Lignite $C$ and Lignite $D$, despite increases in the median particle size from 83 to around $130 \mu \mathrm{m}$, and, in the moisture content from $15 \%$ to $20 \%$, only a $10{ }^{\circ} \mathrm{C}$ rise in MCIT is observed. Lignite $\mathrm{C}$ and $\mathrm{D}$ with similar median particle sizes, volatile and moisture contents represent a cloud ignition temperature of $420{ }^{\circ} \mathrm{C}$. Although these two lignites have distinct ash contents of $5 \%$ and $13 \%$, the result indicates that this $8 \%$ variation in the ash does not reflect any impact on the MCIT for Lignite C and Lignite D.

Surprisingly, Lignite B with properties more susceptible to ignition (D50 of $83 \mathrm{~mm}$, ash content of $5 \%$ and the moisture content of $15 \%$ ) compared to Lignite $C$ and D has a higher MCIT of $440{ }^{\circ} \mathrm{C}$. Considering that Lignite $\mathrm{B}$ and Lignite $\mathrm{C}$ are derived from one mine and only have a different drying degree, a decrease in the median particle size from 140 to $80 \mu \mathrm{m}$ and a $5 \%$ reduction in the moisture content does not show any trend towards a lower MCIT.

Given this finding that a 5\% difference in the moisture content between $15 \%$ to $20 \%$ does not show a notable effect on the cloud ignition temperature and considering a comparable volatile content for the lignites, we concluded that the the low MCIT of Lignite A of $350{ }^{\circ} \mathrm{C}$ is most likely related to its high share of fine particles when compared with other lignites with MCIT of 410 to $440{ }^{\circ} \mathrm{C}$. This highlights the importance of fine particles below $63 \mu \mathrm{m}$ that are considered the critical particle share responsible for ignition [3].

The effect can be related to a change in the ignition mechanism, where it can be assumed that, in larger particles, homogeneous mechanism controls the ignition, while 
as the share of small particles below $63 \mu \mathrm{m}$ are increased, hetero-homogeneous ignition prevails, enhancing the ignition and reducing the ignition temperature. A similar behaviour regarding a drop in the ignition temperature below a specific size was observed by others [19].

To better understand the influence of ash on the MCIT, Lignite A was mixed with combustion-derived ash to produce dust with similar properties but a higher ash content of $15 \%$. Table 3 shows that diluting a dust sample, resulting in a $10 \%$ rise in the ash content, increases the MCIT by $30{ }^{\circ} \mathrm{C}$. A clear inhibiting effect of ash material on the MCIT of lignite A contradicts with the results obtained by Lignite $C$ and Lignite $D$. There are several aspects that need to be considered when interpreting these findings. First, the individual properties of two lignite qualities should be highlighted.

Contrary to a similar chemical composition (except the ash content) and a median particle size, the particle shape, porosity and surface area of Lignite $C$ and Lignite D differ, where the net effect may eventually result in a similar ignition temperature. Table 2 shows that Lignite D has a surface area 11 times larger than that of Lignite C. A larger surface area facilitates the combustion reaction, by enhancing the volatile release from and oxygen diffusion to the surface of particles [6]. This effect may compensate the inhibition effect associated with a higher ash content.

Table 3. Minimum cloud ignition temperature.

\begin{tabular}{ccc}
\hline Fuel & Lignite A+ash & Hard Coal \\
\hline $\operatorname{MCIT~}\left({ }^{\circ} \mathrm{C}\right)$ & 380 & 540 \\
\hline
\end{tabular}

The second aspect refers to the point that the inhibition mechanism of combustionderived admixed ash differs from that of the inherent ash of coal dust. The inert materials are considered as a heat sink source during the ignition. The heat sink occurred by ash hinders the ignition process via various pathways. The single admixed ash particles directly absorb the convective heat from the surrounding. Consequently, the air temperature in the vicinity of coal particles is reduced which impairs the heating process of particles. In addition to convective heat absorption, ash particles dissipate the heat produced via the initial exothermic combustion reactions, which, in return, limits further volatile release by the remaining non-reacted particles and hampering the ignition process $[8,20,21]$.

In addition to the heat dissipation, ash particles can play a blocking role in homogeneous ignition by hindering the mass and heat transfer in the dust cloud $[20,22]$. In addition to the blockage and heat sink inhibiting effect of inert material, ash particles may interfere with the heterogeneous ignition process. The deposition of $\mathrm{Al}_{2} \mathrm{O}_{3}$-containing ash material on the surface of coal particles can further curb the solid-gas heat and mass transfer via the formation of a coating film on the surface of coal particle. Hence, this limits the oxygen attack to and volatile release from the solid surface [22].

On the contrary, inherent ash in coal does not have a strong inhibiting effect as admixed ash, since the ash material are not dispersed as separate particles in the dust cloud. Thus, the available heat is directly absorbed from the surface of coal particles, leading to the volatile release and ignition initiation. A small portion of ash material on the particle's outer surface consumes the heat during the heating and devolatilization process, and an ash layer on the surface of particle will grow as the combustion proceeds. The major portion of ash is then partially released from the char surface and contributes to a larger heat consumption once the ignition is initiated. Under such circumstances, the degree of heat loss associated with ash is insignificant compared to the heat production by the combustion. Accordingly, the deposition of ash layers on the particle surface is mainly relevant after the initial ignition.

Table 3 also shows the MCIT of a commercially available hard coal with a particle size distribution similar to Lignite A. The hard coal is compared with Lignite A to assess the effect of volatiles on the MCIT. The result shows an approximately $200{ }^{\circ} \mathrm{C}$ increment 
in the MCIT to $540{ }^{\circ} \mathrm{C}$ when the volatile content reduces from $48 \%$ in lignite A to $26 \%$ in hard coal.

The comparison of six lignite qualities and one hard coal shows no clear influence on the MCIT when the moisture and ash content varies in a small range of $5 \%$ to $10 \%$. However, a strong relationship is observed between the ignition temperature and the volatile content. Furthermore, differences in the median particle size in the range of 80 to $140 \mu \mathrm{m}$ did not show any clear impact on the MCIT of different lignite qualities. Once the median particle size is decreased to $30 \mu \mathrm{m}$, the MCIT is considerably reduced. The findings highlight that MCIT is more susceptible to the fine share of particles and the fuel's volatile content, whereas it is not significantly impacted by variations within a narrow range of moisture and ash contents in different lignite qualities.

\subsection{Explosion Characteristics}

\subsubsection{The Rate of Pressure Rise}

Figure 2 illustrates the rate of pressure rise for six lignite qualities and one hard coal. The rate of pressure rise for Lignite A and lignite $\mathrm{F}$ are the highest and lowest, respectively, under all dust concentrations among those tested. This behaviour agrees with the trend observed by MCIT and suggests that Lignite A and Lignite F has the highest and lowest ignitability according to both criteria. Lignite A reaches a maximum rate of pressure rise of about $520 \mathrm{bar} / \mathrm{s}$ at an equivalence ratio of 4 , and the maximum value for Lignite $\mathrm{F}$ with $115 \mathrm{bar} / \mathrm{s}$ is reached at an equivalence ratio of 2 .

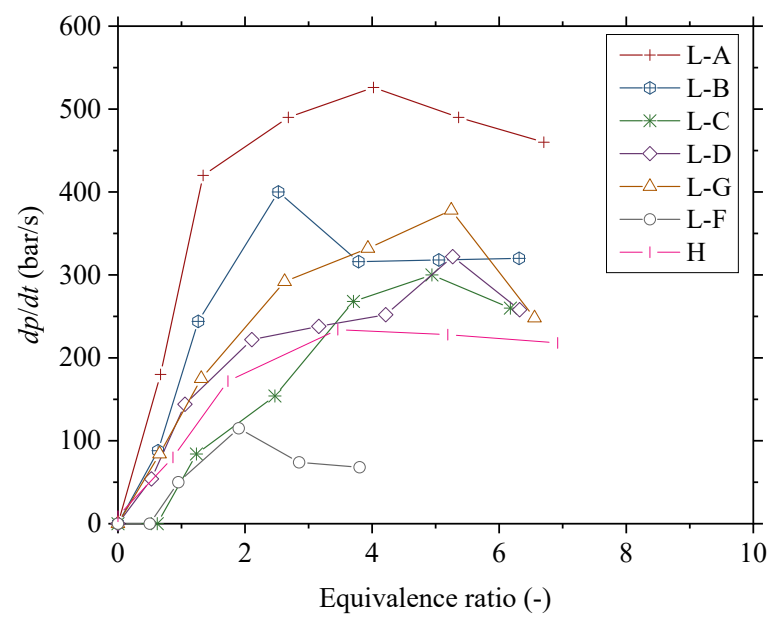

Figure 2. Rate of pressure rise versus the equivalence ratio.

The $d p / d t$ values of Lignite B stay below those obtained by Lignite A. The $d p / d t$ of Lignite B reaches its maximum of $400 \mathrm{bar} / \mathrm{s}$ at the equivalence ratio of 2.5. The values corresponding to Lignite $G$ are lower than those of Lignite $B$ when the latter has an ascending trend, reaching a maximum rate of pressure rise of $378 \mathrm{bar} / \mathrm{s}$ at a high equivalence ratio of 5 .

The $d p / d t$ values for Lignite C are slightly lower than those for Lignite $\mathrm{D}$ until the equivalence ratio of appropriately 3 and then become comparable within an equivalence ratio range of 3 to 6 , where both dusts reach their maximum rate of pressure rise. Lignite $D$ reaches a slightly higher $(d p / d t)_{\max }$ value of $322 \mathrm{bar} / \mathrm{s}$ at the equivalence ratio of 5.3 , while Lignite $\mathrm{C}$ reaches close to $300 \mathrm{bar} / \mathrm{s}$ at the equivalence ratio of 5 . The trends of $d p / d t$ for Lignite $C$ and Lignite D are overall considered comparable, suggesting that these two coal qualities have relatively similar heat release rates and reaction rates, despite their difference in the ash content and the specific surface area.

To precisely assess the influence of ash and inert materials on the combustion kinetics and the heat release rate, Figure 3 compares the $d p / d t$ of Lignite A with the admixed dust. Lignite A with $5 \%$ ash shows a higher $d p / d t$ over all dust concentrations with a 
$(d p / d t)_{\max }$ of $525 \mathrm{bar} / \mathrm{s}$ compared with $470 \mathrm{bar} / \mathrm{s}$ for the sample with $15 \%$ ash. The inert ash's inhibiting effect on the combustion kinetics and heat release rate is clearly observed and is consistent with the literature $[8,20,23]$. Thus, it can be speculated that for Lignite $\mathrm{D}$, a larger surface area alleviates the detrimental effects of high ash content on the combustion rate and oxygen diffusion.

The $d p / d t$ trend of hard coal lies between the trends of lignites, where it reaches its maximum of $234 \mathrm{bar} / \mathrm{s}$ at the equivalence ratio of 3.5. This indicates that, when ignition occurs, the hard coal's heat release rate is comparable to those of certain lignite qualities.

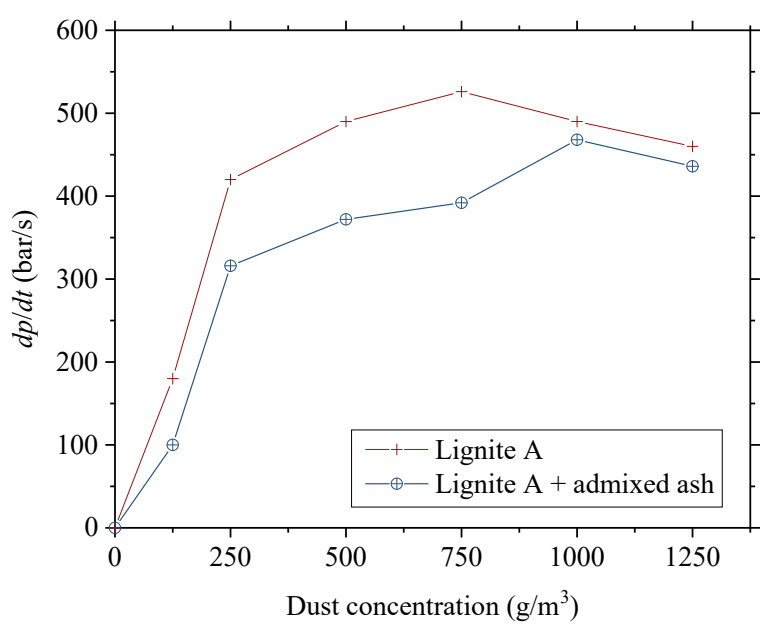

Figure 3. The rate of pressure rise for Lignite A with a $5 \%$ and a $15 \%$ ash content.

\subsubsection{Maximum Explosion Pressure}

The $p_{m}$ trends of different lignite qualities and hard coal do not follow that of $d p / d t$. As shown in Figure 4, Lignite B has the highest $p_{\max }$ of $7.7 \mathrm{bar}$, and Lignite $\mathrm{F}$ has the lowest $p_{\max }$ value of $5.6 \mathrm{bar}$. The graphs of the rest of dust samples, including the hard coal, overlap to a large degree, reaching $p_{\max }$ values between $6.6 \mathrm{bar}$ to $6.9 \mathrm{bar}$. The $p_{\max }$ of the hard coal is close to that of Lignite A, indicating a similar amount of heat release during the ignition. Slight variations of $p_{\max }$ for lignites with distinct characteristics suggest that this parameter is not sufficiently sensitive to the changes of physical and chemical properties of the investigated samples.

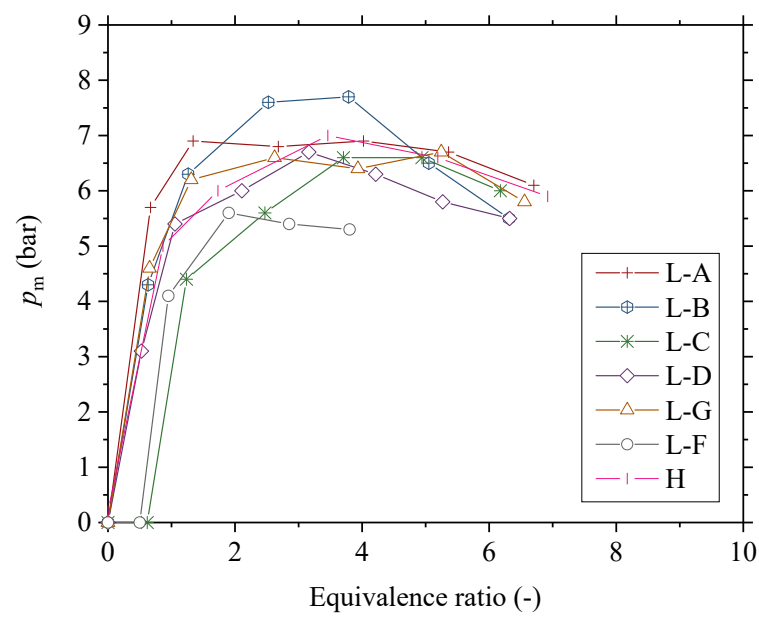

Figure 4. Explosion pressure $\left(p_{\mathrm{m}}\right)$ versus the equivalence ratio.

\subsubsection{The Deflagration Index ( $\mathrm{K}_{\mathrm{st}}$-Value)}

To correlate the lignite properties to the maximum pressure rise, Figure 5 shows the deflagration index in descending order. The trend of $\mathrm{K}_{\mathrm{st}}$-value for different lignites 
is similar to that observed by $(d p / d t)_{\max }$ trends. It is evident that coals with similar moisture contents and median particle sizes demonstrate comparable $\mathrm{K}_{\mathrm{st}}$-values, and the deflagration index sinks as the median particle size and the moisture content rise. Since, within the tested samples, the moisture and particle size vary concurrently, it is challenging to differentiate their contribution to the $\mathrm{K}_{\mathrm{st}}$-value.

According to Segers et al. [24], where a similar lignite quality was used, sieving with $63 \mu \mathrm{m}$ and $500 \mu \mathrm{m}$ mesh sizes, producing a particle size distribution with a median diameters of $28 \mu \mathrm{m}$ and $137 \mu \mathrm{m}$, respectively, showed no considerable impact on the $\mathrm{K}_{\mathrm{st}}$-value. From the above study, we deduced that, mainly, the fine particles account for the initial ignition and govern the $\mathrm{K}_{\mathrm{st}}$-value, where the coarser particles have limited contribution in the combustion process within the 20-litre sphere chamber.

The study indicated that, when a sufficient amount of fine particles is available, the $\mathrm{K}_{\mathrm{st}}$-value is independent of the amount of fine particles, as the samples with $Q_{63}$ of $91 \%$, $36 \%$ and $22 \%$ showed comparable $\mathrm{K}_{\mathrm{st}}$-values [24]. This behaviour of deflagration index with respect to the fine particles was also highlighted in literatures $[6,25]$. Therefore, it can be concluded that the impact of the median particle size on the deflagration index is less significant when the median diameter changes within the coarse particle share, namely above the critical particle share of $63 \mu \mathrm{m}$.

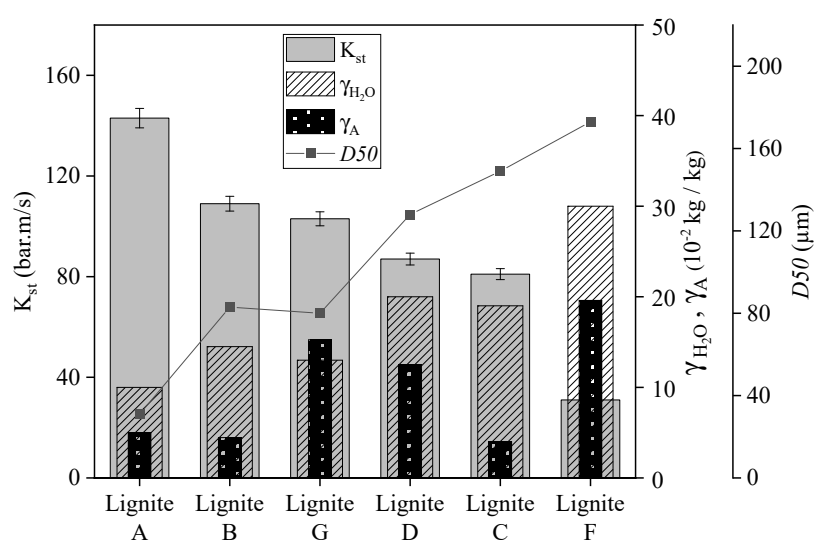

Figure 5. $\mathrm{K}_{\mathrm{st}}$ in descending order, first right axis: moisture and ash content, second right axis: median particle size.

For the lignites investigated, the moisture content demonstrates a decisive factor influencing the heat release rate on a larger degree than the median particle size. A direct comparison between Lignite $B$ and $C$ with distinctive drying degrees, neglecting the difference in the median particle size, shows a reduction of around $30 \mathrm{barm} / \mathrm{s}$ in the $\mathrm{K}_{\mathrm{st}}-\mathrm{v}$ alue when the moisture is increased from $15 \%$ to $20 \%$. Similarly, the $\mathrm{K}_{\mathrm{st}}$-value of lignites with comparable moisture content, Lignite B and G compared with Lignite D and $\mathrm{C}$, remain very close.

The $\mathrm{K}_{\mathrm{st}}$-value shows no clear correlation to the coal ash content. Although a lower $\mathrm{K}_{\mathrm{st}}$-value is expected by Lignite A with admixed ash compared to the original sample (see Figure 3), no concrete detrimental effect can be found when comparing the lignite qualities investigated. Like other criteria, Lignite $\mathrm{F}$ with the highest ash and moisture content and the largest median particle size exhibits the lowest $\mathrm{K}_{\mathrm{st}}$-value.

\subsection{Modified Ignitability Characteristic Number $\left(\mathrm{ZWZ}_{\text {mod. }}\right)$}

Figure 6 shows the devolatilization degree on the left axis and the net energy liberated during the devolatilization (ignition potential) and the energy content of the volatiles released from lignites and the hard coal on the right axis. Lignites represent a devolatilization degree in a narrow range of $60 \%$ to $70 \%$, while this value is reduced to around $40 \%$ for the hard coal. As expected, the devolatilization degree decreases as the volatile content and 
coal rank reduces from lignite to hard coal. The energy of volatiles represents the quantity of the heat released for each unit mass of volatiles.

Figure 6 highlights that the volatiles released from Lignite A, lignite B and Lignite $C$ have a higher calorific value than those released from Lignite $G$, lignite $D$ and Lignite F. Compared to all lignites, the hard coal produces volatiles with the highest calorific value. This behaviour is correlated to the coal intrinsic characteristic and, consequently, the composition and the type of volatiles formed and liberated during the devolatilization.

The ignition potential is slightly decreased from Lignite A to Lignite B and Lignite C. In contrast, a large drop in the ignition potential is observed between Lignite $C$ and Lignite $\mathrm{G}$, followed by slight declines towards Lignite D and Lignite F. Although the calorific value of the volatiles released during hard coal devolatilization is considerably higher than those of lignites, a low volatile content and a low devolatilization degree led to a small ignition potential for the hard coal.

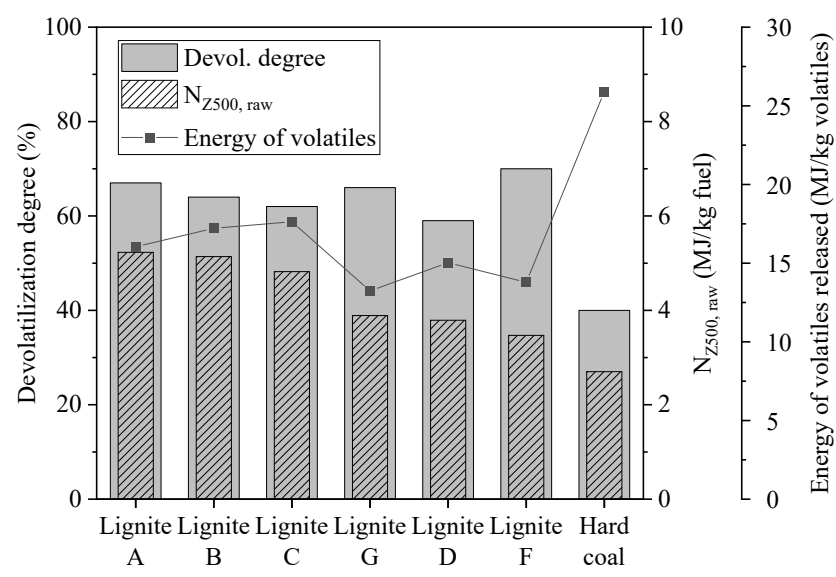

Figure 6. The devolatilization degree and ignition potential of lignites and the hard coal.

The ignitability characteristic number correlates the devolatilization behaviour of the coal to the MCIT. Figure 7 displays the modified ignitability characteristic numbers of lignites in descending order. Here, again, Lignite $\mathrm{A}$ and Lignite $\mathrm{F}$ demonstrate the largest and smallest $Z W Z_{\text {mod. }}$ of around $15 \mathrm{~kJ} / \mathrm{kg}^{\circ} \mathrm{C}$ and $7.5 \mathrm{~kJ} / \mathrm{kg}^{\circ} \mathrm{C}$, respectively. As the moisture content and the median particle size are increased from Lignite A to Lignite $\mathrm{B}$, the $\mathrm{ZWZ}$ mod. is notably decreased to $11.7 \mathrm{~kJ} / \mathrm{kg}^{\circ} \mathrm{C}$.

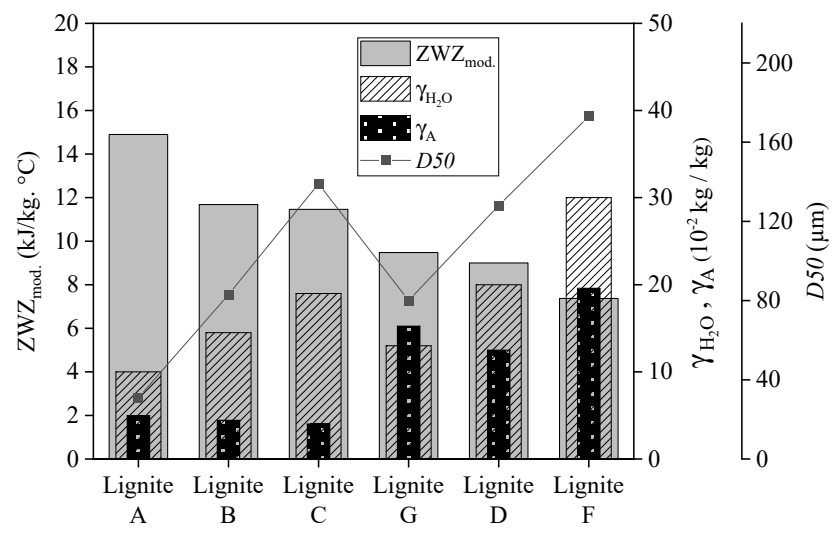

Figure 7. The modified ignitability characteristics number, first right axis: moisture and ash content, second right axis: median particle size.

Excluding Lignite A, Figure 7 exhibits no correlation between the $\mathrm{ZWZ}_{\text {mod. }}$ and the median particle size. The reason is attributed to the fact that neither the numerator nor denominator term demonstrate a strong relationship to the median diameter. As 
discussed in Section 3.1, the MCIT does not change considerably as the median particle size varies within a narrow range of coarse particle sizes. Moreover, the ignition potential is determined under steady-state conditions with a gradual increase in the devolatilization temperature. Consequently, the influence of the particle size on the devolatilization degree is less relevant, as all particle sizes have sufficient time for the devolatilization process.

As moisture is increased by $5 \%$ from Lignite B to Lignite C, a slight reduction is observed in the $\mathrm{ZWZ}_{\text {mod. }}$. Although the ignition potential of Lignite $\mathrm{B}$ is higher than that of Lignite C, a higher MCIT obtained by Lignite B is responsible for this trend. Despite a reduction in the moisture content from Lignite $C$ to Lignite $G$, the $Z W Z_{\text {mod. falls to around }}$ $9.5 \mathrm{~kJ} / \mathrm{kg}^{\circ} \mathrm{C}$, which is related to the difference in the quality of the released volatile as discussed earlier. The $\mathrm{ZWZ}_{\text {mod. }}$ reduces slightly to $9 \mathrm{~kJ} / \mathrm{kg}^{\circ} \mathrm{C}$ when the moisture content and ash content in increased in Lignite D to $20 \%$ and $12 \%$, respectively.

Considering Lignite $B$ and $C$ in one group and Lignite $G$ and D in another, the decrement in $\mathrm{ZWZ}_{\text {mod. }}$ within each group, related to a higher moisture content, is insignificant

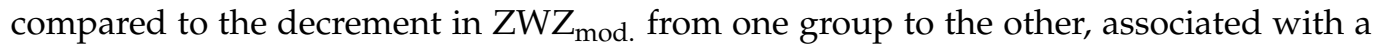
higher ash content and lower quality volatiles. As explained in Figure 6, Lignite B and Lignite $C$ release volatiles with higher calorific values compared to lignite $G$ and Lignite $D$.

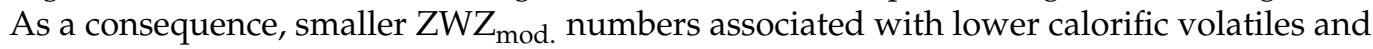
presumably higher ash contents are obtained for the latter group.

In addition, the ignitability characteristic number is significantly influenced by the volatile content, where for the hard coal a low ignition potential and a high MCIT results

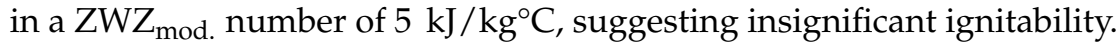

\subsection{Comparison of Ignition Characteristic Parameters with the Ignition Performance at Pilot-Scale}

The coal dusts investigated above are tested in a pilot-scale plasma ignition system to assess their applicability for ignition and self-sustained flame formation under cold start-up burner conditions [14]. Among the investigated parameters, the $\mathrm{K}_{\mathrm{st}}$-value and $\mathrm{ZWZ}_{\text {mod. }}$ were found as the most relevant criteria representing the ignitability among different fuel properties.

Figures 8 and 9 correlate the results of pilot-scale experiments to the $Z W Z_{\text {mod. }}$ number and $K_{s t}$-values, respectively. The parameters are plotted versus the median particle size of the $2 \mathrm{~mm}$-sieved sample used for the pilot-scale experiments. The colour of each fuel addresses the highest Combustion Class obtained with a $4 \mathrm{~kW}$ plasma power. As can be seen, Lignite A and Lignite B with the highest ignitability parameters also show the most promising performance in the plasma ignition system by achieving Combustion Class 6 . As the $\mathrm{ZWZ}_{\text {mod. }}$ number and $\mathrm{K}_{\mathrm{st}}$-value drop for Lignite $\mathrm{C}$ and Lignite $\mathrm{D}$, the performance in the plasma ignition system deteriorates to Combustion Class 5.

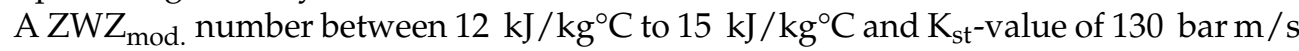
to $140 \mathrm{bar} \mathrm{m} / \mathrm{s}$ suggest fuels qualities with potentials to reach Combustion Class 6 . Fuels

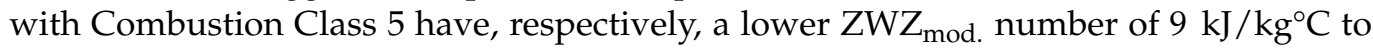
$12 \mathrm{~kJ} / \mathrm{kg}^{\circ} \mathrm{C}$ and $\mathrm{K}_{\mathrm{st}}$-value of $80 \mathrm{barm} / \mathrm{s}$ to $90 \mathrm{barm} / \mathrm{s}$.

Comparing Lignite C and Lignite B with Combustion Class of 5 and 6, respectively, the performances are clearly characterized by $\mathrm{K}_{\mathrm{st}}$-value, whereas $\mathrm{ZWZ}_{\text {mod. }}$ is less relevant to show this difference. The performance of Lignite $G$ and Lignite $F$ in the pilot-scale experiments do not correlate with the characteristic numbers. Particularly for Lignite G, this is related to a large deviation between the particle sizes of the sample used for the dust explosion tests and the pilot-scale test.

The dust explosion tests show a high potential for Lignite $G$ when it has a median particle size below $500 \mu \mathrm{m}$, while it cannot be ignited properly as the particle size is increased. We assumed that a high share of coarse particles impaired the ignition process.

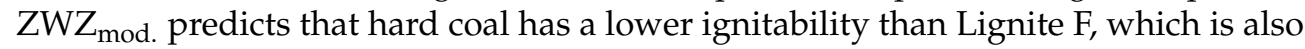
validated by the pilot-scale experiments. In contrast, according to $\mathrm{K}_{\mathrm{st}}$-value Lignite $\mathrm{F}$ has a lower performance compared to hard coal. This shows that $\mathrm{ZWZ}_{\text {mod. }}$ is more relevant 
for characterizing ignition based on their volatile content. At the same time, $\mathrm{K}_{\mathrm{st}}$-value is a more representative parameter when high moisture hinders the ignition.

To conclude, both parameters predict the ignitability of dust samples to a good degree when the median particle size stays below $500 \mu \mathrm{m}$ and can be used as parameters to predict the ignition performance under an industrially-relevant configuration using plasma-assisted ignition.

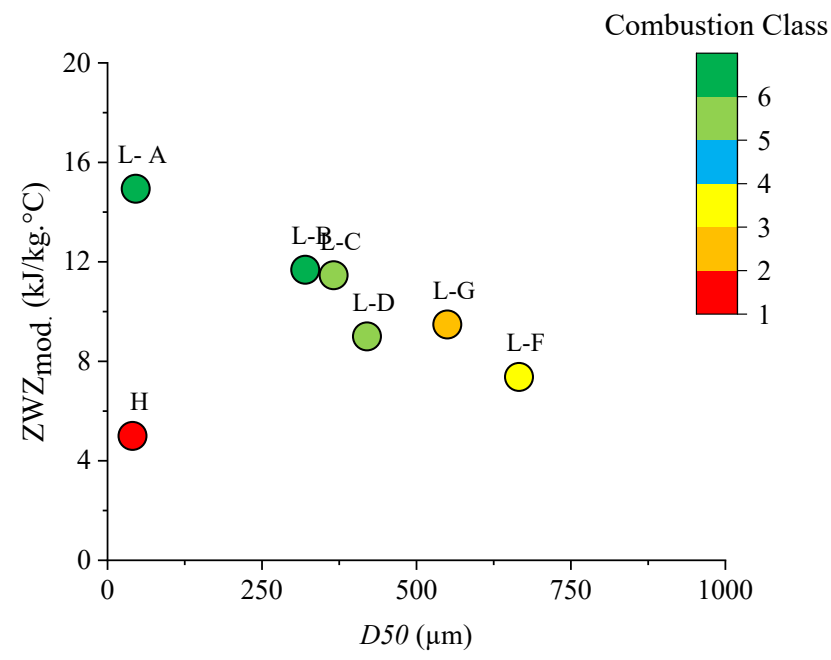

Figure 8. The Combustion Class versus the modified ignitability characteristic number.

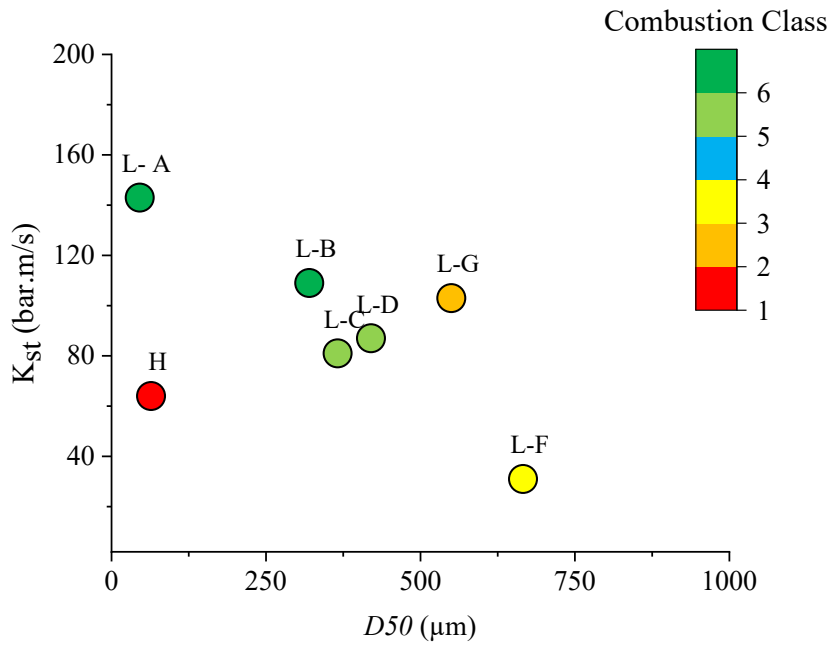

Figure 9. The Combustion Class versus the deflagration index.

The results show that $Z W Z_{\text {mod. }}$ and $K_{\text {st }}$-value parameters have sufficient sensitivity to the ignitability of different lignite qualities. The correlation of these standard parameters to the ignition performance at an industrially-relevant environment proved the applicability of using these numbers for the pre-evaluation of the ignition performance and suggests that such characteristic numbers can be transferred into larger-scale applications. For the application of plasma-assisted ignition of pulverized fuel, this method can be used to narrow down the compatible fuel qualities. Although this preliminary study shows promising results for considering these parameters as indications of ignition performance, to further validate this approach, additional experiments with a large variety of fuel types and qualities need to be carried out. 


\section{Conclusions}

The MCIT, $d p / d t, p_{\max }, \mathrm{K}_{\mathrm{st}}$-value and $\mathrm{ZWZ}_{\mathrm{mod}}$. were determined for six lignite dust qualities and one hard coal where the following outcomes were obtained.

- The MCIT for four lignite qualities with $10 \%$ to $20 \%$ moisture content, $5 \%$ to $15 \%$ ash content and median diameters of 83 to $150 \mu \mathrm{m}$ changed in a narrow range of 410 to $440{ }^{\circ} \mathrm{C}$ and did not show a clear correlation to these properties within this range. A $10 \%$ increase in the ash content by combustion-derived admixed ash showed a $30{ }^{\circ} \mathrm{C}$ increase in the MCIT. This highlights the importance of the available surface area and different ignition inhibition mechanisms of intrinsic ash and admixed ash when different coal dust types are compared. As the median particle size is considerably reduced to $45 \mu \mathrm{m}$, a high share of fine particles compared to other lignite qualities showed a large reduction in the MCIT to $350{ }^{\circ} \mathrm{C}$. An increase in the moisture content to $30 \%$ and in the ash content to $20 \%$ in Lignite F increased the MCIT to $470{ }^{\circ} \mathrm{C}$.

- The maximum explosion pressure did not represent any clear interdependence to the physical and chemical properties of the investigated dust qualities and, therefore, was not found suitable to be used as an ignition characterization parameter.

- The deflagration index showed a strong dependency on the moisture content and was more susceptible to changes as the dust properties varied. Lignite A and Lignite F had the largest and the smallest $\mathrm{K}_{\mathrm{st}}$-value among the tested dust qualities. Lignite $\mathrm{B}$ and Lignite $\mathrm{G}$ with $10 \%$ moisture had higher $\mathrm{K}_{\mathrm{st}}$-values than Lignite $\mathrm{C}$ and Lignite $\mathrm{D}$ with a moisture content of $20 \%$. Similar to MCIT, the admixed ash reduced the $\mathrm{K}_{\mathrm{st}}$-value, but no clear correlation between the ash content of different lignite dusts and the $\mathrm{K}_{\mathrm{st}}$-value was found.

- The modified ignitability characteristic number correlated the released energy during the devolatilization to the ignition temperature. This parameter considers the devolatilization degree and the calorific value of the released volatiles. The results showed that Lignite A, Lignite $B$ and Lignite $C$ produce volatile materials with higher calorific values than Lignite D, Lignite $\mathrm{G}$ and Lignite $\mathrm{F}$ as well as correspondingly higher $\mathrm{ZWZ}_{\text {mod. }}$ values. The latter group has also higher ash content compared to the former one. The ignition potential is slightly reduced as the moisture is increased from Lignite A to Lignite $\mathrm{C}$. However, $\mathrm{ZWZ}_{\text {mod. }}$ drops significantly as the median particle size increases from Lignite A to Lignite $B$ and Lignite $C$, related to an increase in the ignition temperature. Overall, $\mathrm{ZWZ}_{\text {mod. }}$ did not show an evident correlation to the median particle size.

- $\quad \mathrm{K}_{\mathrm{st}}$-value and $\mathrm{ZWZ}$ mod. were observed to have a higher sensitivity to the changes in fuel properties and, therefore, were correlated to the ignition performance in the pilotscale experiments. Both parameters showed satisfactory correlation to the ignition performance in the pilot-scale testing and can potentially be used as indicators to predict dedicated dust quality ignition performance for the investigated application. For each parameter, an approximate range can be determined based on the ignition performance defined by different Combustion Classes. However, this argument is only valid when the dust quality has a sufficient share of fine particles. The share of fine particles is a critical parameter necessary for the ignition initiation.

This study should be further expanded within a larger case study in which different ranks of solid fuels, such as high- and low-volatile hard coal and biomass qualities, are investigated. The critical parameters that represent the ignition characteristics and also the relevance of the parameters to the ignition performance at an industrially-relevant environment need to be identified for this extended case study.

Author Contributions: Conceptualization, R.Y., J.M. and F.N.; methodology, T.S. and F.N.; formal analysis, R.Y. and T.S.; investigation, R.Y. and J.M.; writing—original draft preparation R.Y.; writingreview and editing, R.Y., T.S., F.N. and G.S.; visualization, R.Y.; supervision, J.M. and G.S. All authors have read and agreed to the published version of the manuscript.

Funding: The research received no external funding. 
Institutional Review Board Statement: Not applicable.

Informed Consent Statement: Not applicable.

Acknowledgments: The authors would like to thank Adinex N.V., especially Filip Verplaetsen, for his support and guidance.

Conflicts of Interest: The authors declare no conflict of interest.

\section{Abbreviations}

The following nomenclature are used in this manuscript:

$\begin{array}{ll}\begin{array}{l}\text { Symbol } \\ a\end{array} & \begin{array}{l}\text { Unit } \\ \mathrm{m}^{2} / \mathrm{g}\end{array} \\ D 10 & \mu \mathrm{m} \\ D 50 & \mu \mathrm{m} \\ D 90 & \mu \mathrm{m} \\ d p / d t & \mathrm{bar} / \mathrm{s} \\ (d p / d t)_{\max } & \mathrm{bar} / \mathrm{s} \\ \gamma_{i} & 10^{-2} \mathrm{~kg} / \mathrm{kg} \\ \mathrm{K}_{\mathrm{st}} & \mathrm{bar} \mathrm{m} / \mathrm{s} \\ \mathrm{MCIT} & { }^{\circ} \mathrm{C} \\ \mathrm{NCV} & \mathrm{MJ} / \mathrm{kg} \\ \mathrm{N}_{\mathrm{Z} 500} & \mathrm{MJ} / \mathrm{kg} \\ p_{\mathrm{m}} & \mathrm{bar} \\ p_{\max } & \mathrm{bar} \\ Q_{63} & \% \\ \mathrm{ZWZ}_{\text {mod. }} & \mathrm{kJ} / \mathrm{kg}^{\circ} \mathrm{C}\end{array}$

Quantity

Specific surface area based on BET method The particle diameter where $10 \%$ of the distribution has a smaller particle size Median particle size The particle diameter where $90 \%$ of the distribution has a smaller particle size The rate of pressure rise The maximum rate of pressure rise Mass fraction of the material $i$ in the fuel Deflagration index Minimum cloud ignition temperature Net calorific value Ignition potential Explosion pressure Maximum explosion pressure Cumulative particle size distribution at the particle size of $63 \mu \mathrm{m}$ modified ignitability characteristics number

\section{References}

1. Messerle, V.E.; Karpenko, E.I.; Ustimenko, A.B.; Lavrichshev, O.A. Plasma preparation of coal to combustion in power boilers. Fuel Process. Technol. 2013, 107, 93-98. [CrossRef]

2. Heimann, G. Erfolgreiche Installation und Inbetriebnahme einer Zünd- und Stützfeuerung mittels Trockenbraunkohlebrenner mit Plasmazündung. VGB PowerTech 2016, 7, 40-44.

3. Zelkowski, J.B. Kohlecharakterisierung und Kohleverbrennung, 2nd ed.; VGB PowerTech Service GmbH: Essen, Germany, 2004.

4. Torrent, J.G.; Armada, I.S.; Pedreira, R. A correlation between composition and explosibility index for coal dust. Fuel 1988, 67, 1629-1632. [CrossRef]

5. García-Torrent, G.; Cantalapiedra-Fuchs, J.; Montes-Villalón, R.; Alcántara-Pedreira, R. Improvement in the correlation between the composition index and the explosibility index for coal dust. Fuel 1991, 70, 1099-1101. [CrossRef]

6. Cashdollar, K.L. Overview of dust explosibility characteristics. J. Loss Prev. Process Ind. 2000, 13, 183-199. [CrossRef]

7. Abbasi, T.; Abbasi, S.A. Dust explosions-cases, causes, consequences, and control. J. Hazard. Mater. 2007, 140, 7-44. [CrossRef] [PubMed]

8. Amyotte, P.R. Solid inertants and their use in dust explosion prevention and mitigation. J. Loss Prev. Process Ind. 2006, 19, 161-173 [CrossRef]

9. Fernandez-Anez, N.; Slatter, D.J.F.; Saeed, M.A.; Phylaktou, H.N.; Andrews, G.E.; Garcia-Torrent, J. Ignition sensitivity of solid fuel mixtures. Fuel 2018, 223, 451-461. [CrossRef]

10. Yuan, J.; Wei, W.; Huang, W.; Du, B.; Liu, L.; Zhu, J. Experimental investigations on the roles of moisture in coal dust explosion. J. Taiwan Inst. Chem. Eng. 2014, 45, 2325-2333. [CrossRef]

11. Kurose, R.; Tsuji, H.; Makino, H. Effects of moisture in coal on pulverized coal combustion characteristics. Fuel 2001, 80, 1457-1465. [CrossRef]

12. Eckhoff, R.K. Influence of dispersibility and coagulation on the dust explosion risk presented by powders consisting of nmparticles. Powder Technol. 2013, 239, 223-230. [CrossRef]

13. Traoré, M.; Dufaud, O.; Perrin, L.; Chazelet, S.; Thomas, D. Dust explosions: How should the influence of humidity be taken into account? Process Saf. Environ. Prot. 2009, 87, 14-20. [CrossRef]

14. Youssefi, R.; Maier, J.; Scheffknecht, G. Pilot-Scale Experiences on a Plasma Ignition System for Pulverized Fuels. Energies 2021, 14, 4726. [CrossRef]

15. VDI Verein Deutscher Ingenieure e.V. VDI 2263:2003-05-Dust Fires and Dust Explosions Hazards-Assessment-Protective MeasuresPart 1: Test Methods for the Determination of the Safety Characteristic of Dusts; VDI: Düsseldorf, German, 1990. 
16. DIN Deutsches Institute für Normung e.V. DIN EN ISO/IEC 80079-20-2:2016-12-Explosive Atmospheres-Part 20-2: Material Characteristics-Combustible Dusts Test Methods; DIN: Berlin, Germany, 2016.

17. DIN Deutsches Institute für Normung e.V. DIN EN 14034-1:2011-04—Determination of Explosion Characteristics of Dust Clouds—Part 1: Determination of the Maximum Explosion Pressure Pmax of Dust Clouds; DIN: Berlin, Germany, 2011.

18. DIN Deutsches Institute für Normung e.V. DIN EN 14034-2:2011-04—Determination of Explosion Characteristics of Dust Clouds—Part 2: Determination of the Maximum Rate of Explosion Pressure Rise (dp/dt)max of Dust Clouds; DIN: Berlin, Germany, 2011.

19. Ajrash, M.J.; Zanganeh, J.; Moghtaderi, B. The effects of coal dust concentrations and particle sizes on the minimum auto-ignition temperature of a coal dust cloud. Fire Mater. 2017, 41, 908-915. [CrossRef]

20. Du, B.; Huang, W.; Kuai, N.; Yuan, J.; Li, Z.; Gan, Y. Experimental Investigation on Inerting Mechanism of Dust Explosion. Procedia Eng. 2012, 43, 338-342. [CrossRef]

21. Dastidar, A.G.; Amyotte, P.R.; Pegg, M.J. Factors influencing the suppression of coal dust explosions. Fuel 1997, 76, 663-670. [CrossRef]

22. Yu, H.; Wang, C.; Pang, L.; Cui, Y.; Chen, D. Inhibiting effect of coal fly ash on minimum ignition temperature of coal dust clouds. J. Loss Prev. Process Ind. 2019, 61, 24-29. [CrossRef]

23. Garcia-Torrent, J.; Fernandez-Anez, N.; Medic-Pejic, L.; Blandon-Montes, A.; Molina-Escobar, J.M. Ignition and explosion parameters of Colombian coals. J. Loss Prev. Process Ind. 2016, 43, 706-713. [CrossRef]

24. Segers, T.; Norman, F.; Youssefi, R.; Maier, J.; Verplaetsen, F. The Influence of Sieving on the Dust Explosion Characteristics of a Lignite Coal. Chem. Eng. Trans. 2019, 77, 475-480.

25. Cashdollar, K.L. Coal dust explosibility. J. Loss Prev. Process Ind. 1996, 9, 65-76. [CrossRef] 